\title{
Educação para a humanização: por um trânsito mais consciente ${ }^{1}$ Education for humanization: a plea for a more sensible traffic
}

\author{
Marcos Paulo Cavalcanti dos SANTOS ${ }^{2}$ \\ Patrícia Irene dos SANTOS ${ }^{3}$
}

\begin{abstract}
Resumo: A educação para o trânsito é um dos maiores desafios enfrentados pela sociedade. Este artigo teve por objetivo analisar como a educação para o trânsito vem sendo tratada nos cursos de formação de professores e as concepções que professores possuem acerca da temática. Trata-se de uma abordagem qualitativa de pesquisa (MINAYO, 1994). Foram aplicados questionários (GIL, 1999) com seis professoras, sendo duas egressas do curso de Pedagogia e quatro que já atuam com turmas dos anos iniciais da rede municipal de Recife - Pernambuco. Para análise dos dados coletados, utilizamos a Análise de Conteúdo (BARDIN, 2002). Os resultados apontaram que a educação para o trânsito não vem sendo abordada como conteúdo curricular nos cursos de formação inicial de professores, nem como temática nas formações continuadas. Das seis professoras pesquisadas, apenas uma afirmou ter participado de um curso para multiplicadores. Elas sinalizaram a influência que a educação para o trânsito exerce na redução e prevenção de acidentes, inclusive afirmando que é fator primordial a ser trabalhado desde a educação infantil. Cinco professoras revelaram não desenvolverem ações ou projetos que envolvem a educação para o trânsito. No entanto, a pertinência desse assunto também foi pontuada na importância da formação para a cidadania dos seus alunos, que mesmo sem formação específica, se revelam preocupadas no seu cotidiano em orientá-los, utilizando-se de iniciativa e conhecimentos próprios. Com isto, consideramos que a pesquisa apresentou resultados positivos, por contribuir tanto com a ampliação do conhecimento empírico como uma releitura acerca dos aspectos legais.
\end{abstract}

Palavras-chave: Educação. Formação. Humanização. Trânsito.

Resumo: Traffic education is one of the greatest challenges faced by society. This article aims to analyze how traffic education has been addressed in teacher education courses and the teachers' conceptions about the subject matter. This is a qualitative research approach (MINAYO, 1994). Questionnaires were applied (GIL, 1999) with six female teachers, two from the Teacher Education course and four Professional ones teaching the initial years of the municipal school system of Recife - Pernambuco. To analyze the data collected it was used the Content Analysis (BARDIN, 2002). The results pointed out that traffic education has not been approached as curricular content in the initial Teacher Education courses, or as a theme in the continuing education. Of the six teachers surveyed, only one reported participating in a multiplier effect course. They signaled the influence of traffic education on the reduction and prevention of accidents, including stating that it is a primary factor to be worked specially concerning children education. Five teachers revealed that they did not develop actions or projects involving traffic education. However, the relevance of this subject matter was also higlighted the importance of the students' citizenship development, who even without specific knowledge on the subject matter, they show preoccupation concerning their daily life in guiding them to make use of their own initiative and awareness. Thus, we consider that the research presented positive results by contributing with both the expansion of empirical knowledge and a re-reading about the legal aspects.

Keywords: Education. Formation. Humanization. Traffic.

http://dx.doi.org/10.24024/23585188v12n1a2019p950101

\footnotetext{
${ }^{1}$ Trabalho comtemplado com o 1ㅇ Prêmio Detran/PE de Educação para o Trânsito, na categoria artigo científico, em 20 de dezembro de 2017.

${ }^{2}$ Psicólogo pela Faculdade Frassinetti do Recife - FAFIRE | E-mail: paulocavalcantipsi@gmail.com

${ }^{3}$ Doutoranda em Educação na linha de pesquisa Formação de Professores e Prática Pedagógica pela UFPE. Professora dos anos iniciais pela Rede Municipal de Recife e na licenciatura em Pedagogia pela Faculdade Frassinetti do Recife - FAFIRE | E-mail: patriciareflexao@gmail.com
} 


\section{Introdução}

Diante dos altos índices de acidentes de trânsito e das campanhas de conscientização para um trânsito seguro veiculadas pela mídia, nos reportamos à Lei no 9.503, de 23 de setembro de 1997, que institui o Código de Trânsito Brasileiro. O Art. 76 instrui que a Educação para o Trânsito deve ser ofertada desde a pré-escola até o ensino superior. $O$ grande desafio que se coloca a partir desse aspecto legal é sinalizado no item II do parágrafo único deste artigo, quando se refere à adoção de conteúdos relativos à educação para o trânsito nas escolas de formação para o magistério e o treinamento de professores e multiplicadores.

Todos esses fatos nos permitem levantar a seguinte hipótese: que a mesma lei que afirma que o conteúdo referente à Educação para o trânsito seja promovido na pré-escola e nas escolas de 1으, 2으 e 3으 graus não garante mecanismos de acompanhamento que assegurem seu funcionamento. A expectativa que temos é que, se este mecanismo funcionasse, os professores poderiam, durante seu processo formativo, criar um leque de conhecimentos para melhor trabalhar a temática da educação para o trânsito.

Tal desafio nos levou a investigar o seguinte problema de pesquisa: como a educação para o trânsito vem sendo tratada nos cursos de formação de professores?

Neste sentido, a pertinência da pesquisa se configura como uma contribuição epistemológica e empírica, visto que os resultados revelam elementos que indicam possíveis caminhos para se repensar a formação de professores no que concerne à educação para o trânsito. Justificamos também a relevância desta pesquisa pela sua interlocução com o debate sobre educar para cidadania, numa perspectiva de humanização do humano.

Partindo dessas premissas, elegeu-se como objetivo geral: analisar como a educação para o trânsito vem sendo tratada nos cursos de formação de professores e as concepções que professores possuem acerca da temática. E como objetivos específicos: verificar como os professores veem a influência da educação para o trânsito na redução e prevenção de acidentes; compreender se os professores receberam (formação inicial) ou recebem (formação continuada) formação sobre educação para o trânsito; identificar se e como os professores desenvolvem ações ou projetos que envolvem a educação para o trânsito nas escolas.

\section{Fundamentação teórica}

A Educação no trânsito é um dos maiores desafios enfrentados pela sociedade. Para Martins (2007, p. 19), "é preciso humanizar a realidade do trânsito, corrigindo os erros com campanhas educativas bem conduzidas e direcionadas pelos diversos meios de comunicação, valendo-se de estratégias diversificadas".

De acordo com Ghiraldelli Jr (2015, p. 13), o termo educar tem origem em duas palavras do latim: "educere e educare", que respectivamente nos transmitem a ideia de conduzir de fora ou dirigir exteriormente e de "sustentar, alimentar e criar", ou como costumamos dizer: "educação é o ato de instruir e ensinar". Partimos da noção de educação porque acreditamos que educar, acima de tudo, é um desafio constante e diário para aqueles que se propuseram se debruçar diante desta função pouco valorizada em nossa sociedade, mas que, ao se desafiar até mesmo em sua formação, o educador, no curso de pedagogia ou nas diversas licenciaturas, sabe que por mais que existam fóruns, debates, congressos, palestras, formação continuada e outros, nunca será suficiente para esgotar o conhecimento necessário para estar diante de uma sala de aula, sendo necessário um investimento constante em sua própria educação.

E é com este pensamento que fomos pesquisar informações a respeito de como vem sendo trabalhada a educação para o trânsito em nossas salas de aula, tendo em mente que se a educação é um ato de ensinar e instruir, por que não falamos sobre educação no trânsito desde os anos iniciais da escolarização?

Nessa mesma perspectiva, é necessário que tenhamos estratégias que considerem a escola como um lugar central de aprendizado. E que se faz necessário que as políticas ultrapassem o limite dos centros de ensino, sendo capazes de envolver a comunidade com temas relacionados à educação no trânsito. Não se pode esperar apenas o período de férias escolares ou a semana nacional do trânsito para abordar esta temática, pois a mesma diz respeito ao nosso dia a dia, quer seja na condição de condutores, motoristas 
ou até mesmo pedestres. Apenas com uma política de Educação preventiva poderemos reduzir significativamente o número de acidentes no Brasil (WERTHEIN, 2007).

Também refletimos sobre como a temática da Educação para o Trânsito vem sendo tratada nos espaços de formação inicial e continuada de professores. A esse respeito, a Resolução no 02 de 01 de julho de 2015, que define as Diretrizes Curriculares Nacionais para formação inicial em nível superior (Cursos de licenciatura, cursos de formação pedagógica para graduados e cursos de segunda licenciatura) e para a formação continuada, sinaliza que:

Art. 7으 $\mathrm{O}(\mathrm{A})$ egresso (a) da formação inicial e continuada deverá possuir um repertório de informações e habilidades composto pela pluralidade de conhecimentos teóricos e práticos cuja consolidação virá do seu exercício profissional, fundamentado em princípios de interdisciplinaridade, contextualização, democratização, pertinência e relevância social, ética e sensibilidade afetiva e estética, de modo a lhe permitir: I - o conhecimento da instituição educativa como organização complexa na função de promover a educação para e na cidadania (BRASIL, Capítulo III, 2015, p. 6-7).

Dessa forma, ao nos reportar aos aspectos legais, podemos averiguar que a Educação no e para Trânsito é tratada na Lei de Diretrizes e Bases da Educação Nacional (LDBEN), na Constituição Federal, no Estatuto da Criança e do Adolescente, no Estatuto do Idoso, nos Parâmetros Curriculares Nacionais (PCN) e no Código de Trânsito Brasileiro (CTB) e suas resoluções. No entanto, defendemos que cabe aos espaços formativos direcionar melhor tal aspecto em seus projetos de curso, a fim de fornecer os subsídios necessários para que a temática da educação para o trânsito seja mais bem abordada na educação básica, como podemos observar abaixo

A respeito dos conteúdos curriculares da educação básica, 0 art. 27, inciso I, da Lei de Diretrizes e Bases da Educação (BRASIL, 1996), esclarece que devem ser observados "a difusão de valores fundamentais ao interesse social, aos direitos e deveres dos cidadãos, de respeito ao bem comum e à ordem democrática". $O$ art. 23 da Constituição da República Federativa do Brasil (BRASIL, 1988) versa sobre as competências comuns da União, dos Estados, do Distrito Federal e dos Municípios. No inciso XII deste artigo, consta como competências das referidas esferas de governos: "estabelecer e implantar política de educação para a segurança do trânsito". Sendo assim, promover a educação para o trânsito é uma lei, e está na Constituição da República Federativa do Brasil.

Em relação ao Estatuto da Criança e do Adolescente (BRASIL, 1990), nos Artigos 15, 16, 17 e 18 está destacado que a criança e o adolescente têm direito à vida, ao respeito, à dignidade, à saúde, a ir e vir e estar com segurança em locais públicos. O Estatuto do Idoso (BRASIL, 2003) prevê os direitos da pessoa idosa, como transporte público, saúde e proteção à vida.

Nos Parâmetros Curriculares Nacionais - PCN (BRASIL, 1997) constam temas transversais que devem ser contextualizados, pelos professores, com os conteúdos curriculares. Os temas transversais são: Ética, Meio Ambiente, Pluralidade Cultural, Saúde e Orientação Sexual. Os PCN estabelecem também a eleição de um tema transversal local e sugerem o trânsito para esse tema.

Por sua vez, no Código de Trânsito Brasileiro (BRASIL, 1997), foi dispensado o Capítulo VI (com seis artigos), exclusivo ao tema Educação para o Trânsito. Neste capítulo destacam-se a criação da coordenação educacional, as campanhas educativas, a educação para o trânsito nas escolas, as campanhas sobre primeiros socorros, as mensagens e programas educativos.

Há, ainda, diversas resoluções que tratam do tema educação para o trânsito, como: a Resolução no 207/2006, que estabelece critérios de padronização para funcionamento das Escolas Públicas de Trânsito; a Resolução no 265/2007, que dispõe sobre a formação teórico-técnica do processo de habilitação de condutores de veículos automotores elétricos como atividade extracurricular no ensino médio e define os procedimentos para implementação nas escolas interessadas; a Resolução no $314 / 2009$, que estabelece procedimentos para a execução das campanhas educativas de trânsito a serem promovidas pelos órgãos e entidades do Sistema Nacional de Trânsito. Ressaltamos, ainda, a 
Portaria no 147/20094, que aprova as Diretrizes Nacionais da Educação para o Trânsito na Pré-Escola e no Ensino Fundamental. Salientamos que os anexos dessa Portaria se constituem em fontes de consulta para os professores direcionarem seus planos de aula.

Segundo dados do Ministério da Saúde (DATASUS 2010), os acidentes de trânsito são os responsáveis pelo maior número de mortes todos os anos. Na mesma linha estatística, conforme a OSCIP (Organização da Sociedade Civil de Interesse Público) de atuação nacional "A Criança Segura", ocorreram, em 2014 (14.150), em 2015 (12.979) e em 2016 (12.288), acidentes de trânsito entre crianças e adolescentes entre 0 e 14 anos de idade. Aqui no estado de Pernambuco são realizados trabalhos de conscientização no trânsito através de campanhas como: Operação Lei Seca e "Turma do Fom-Fom", entre outros. Contudo, ainda é grande o número de acidentes no trânsito.

De acordo com Portal do Trânsito (2017), a partir de dados da Agência Brasil, é relatado que o número de indenizações por morte no trânsito aumentou $27 \%$ no primeiro semestre de 2017, isto em comparação ao ano de 2016. Em contrapartida, o número indenizações por acidente caiu. Essa estatística reforça a importância de uma educação preventiva para que a educação no trânsito e para um trânsito possa ser vista como um valor moral a ser seguido pela população. Ainda, vale ressaltar que os acidentes de trânsito fazem vítimas tanto do lado em que está o condutor como também no lado dos pedestres, pois estes ficam em segundo lugar nas estatísticas de indenizações por morte neste período.

Pensando em como contribuir com a mudança deste quadro, e apesar de acreditamos que ainda é deficitária a aplicabilidade da temática Educação para o Trânsito nos anos iniciais da escolaridade, isto porque se percebe que a preocupação com o tema fica restrita à Semana Nacional do Trânsito e normalmente é esquecido durante os outros períodos do ano, decidimos investigar junto aos professores qual sua opinião sobre como a educação para o trânsito influencia na redução e prevenção de acidentes; se este tema tem sido tratado nas formações continuadas ofertadas pelas redes de ensino; que ações ou projetos são trabaIhados nas escolas.

\section{Metodologia}

Adotamos para este estudo uma abordagem qualitativa de pesquisa, entendendo que ela trabalha com o "universo de significados, motivos, aspirações, crenças, valores e atitudes, o que corresponde a um espaço mais profundo das relações, dos processos e dos fenômenos" (MINAYO, 1994, p. 22).

Nossa amostra foi composta por seis professoras (todas com licenciatura em Pedagogia), sendo duas egressas em 2016 e quatro professoras que atuam em escolas da rede municipal da cidade do Recife, Pernambuco, com mais de 05 anos de experiência. A faixa etária de todas as professoras oscila entre 28 e 39 anos. Para nossa pesquisa serão identificadas com a letra $\mathrm{P}$ (professora), seguido do número de ordem no protocolo do questionário.

O instrumento de coleta utilizado foi o questionário com questões fechadas e abertas. Esse instrumento, segundo Gil (1999, p. 128), pode ser definido "como a técnica de investigação composta por um número mais ou menos elevado de questões apresentadas por escrito às pessoas, tendo por objetivo o conhecimento de opiniões, crenças, sentimentos, interesses, expectativas, situações vivenciadas etc.". As perguntas fechadas nos trarão alternativas específicas para que os professores escolham uma delas. Por sua vez, as perguntas abertas permitirão maior liberdade de respostas, quando, através de linguagem própria, os sujeitos poderão escrever aquilo que lhe vier à mente, interagindo de uma maneira mais espontânea (CHAER; DINIZ; RIBEIRO, 2011). Para o tratamento e análise dos dados coletados, foi utilizada a Análise de Conteúdo do tipo categorial por temática, a qual se efetiva por meio de desmembramento de texto em unidades e categorias para posterior reagrupamento analítico. A análise de conteúdo é "enquan-

\footnotetext{
${ }^{4}$ Encontram-se disponíveis inclusive os anexos que se reportam às Diretrizes Nacionais da Educação para o Trânsito na Pré-escola e no Ensino Fundamental, no site: www.denatran.gov.br
} 
to esforço de interpretação, a análise de conteúdo oscila entre dois pólos: do rigor da objetividade e da fecundidade da subjetividade" (BARDIN, 2002, p. 9). Dito de outra maneira, a análise de conteúdo é uma técnica desenvolvida especificamente para investigar um problema de pesquisa no qual o conteúdo da comunicação sirva de base, portanto, consiste num recurso técnico para análise de dados, sendo proveniente de mensagens escritas ou transcritas.

\section{Análise e discussão dos resultados}

Após o tratamento dos dados, buscamos verificar como os professores veem a influência da educação para o trânsito na redução e prevenção de acidentes e a partir de que modalidade de ensino ela deveria ser oferecida nas escolas. A esse respeito, as professoras afirmaram que "é fator primordial para uma boa convivência", e quando se trata de educação no trânsito "isso se intensifica de forma mais concreta e imediata, sendo assim, quando há uma população consciente, que respeita o direito do outro e sabem quais são seus deveres no trânsito, consequentemente, os números exorbitantes de agressões e acidentes poderão ser reduzidos" (P1). Trata-se de uma questão de "mudar a cultura que temos de imprudência, já que no trânsito vemos o reflexo da sociedade" (P2). "A educação no trânsito desde cedo contribui para a formação de cidadãos mais consciente de sua responsabilidade e respeito no uso do espaço coletivo" (P6).

Dessa forma, a "oportunidade de conscientização" sendo ofertada "desde a educação Infantil" (P3). Tal modalidade de ensino foi indicada por unanimidade pelas professoras, "pois no modelo que vivemos a mobilidade é necessária em qualquer idade", ressalta a professora P2. Ainda sobre este tema, sugerem que deveria "iniciar com ensinamentos mais simples até os mais complexos com os mais velhos, pois eles atuam na sociedade enquanto pedestre indo e vindo com os pais de bicicleta para a escola" (P5) e "tomar consciência de que precisamos compartilhar os espaços com o outro de forma igualitária contribui muito para a boa convivência coletiva" (P6).

Tomada de consciência é aqui compreendida como a consequência da confrontação que o aluno passa a ter com o mundo como algo objetivo e a partir daí perceber que pode e deve transformar a realidade imediata (de exposição aos acidentes) em realidade diária, consciente (de prevenção e redução de acidentes) e de ações solidárias e humanizadoras frente à vida em sociedade (FREIRE, 2006).

Salientamos que as professoras P4 e P6 sinalizaram que este tema deveria ser trabalhado como temas transversais, informação esta que vem direcionada na legislação pertinente. No entanto, chamamos atenção para o fato de que é necessário haver objetivos e planejamento em consonância com o projeto de formação que se pratica ou pretende defender, pois, caso contrário, os temas transversais ficarão restritos às ações pontuais, como é o caso das atividades realizadas em virtude da Semana Nacional do Trânsito.

Percebemos que, apesar de todas as professoras terem sinalizado que não receberam ou recebem formação (inicial e ou continuada) sobre a temática da educação para o trânsito, possuem suas concepções acerca da pertinência desse assunto na importância da formação para a cidadania dos seus alunos, e se revelam preocupadas, no seu cotidiano, em orientá-los, utilizando-se de iniciativa e conhecimentos próprios, como argumenta a professora P5, ao afirmar: "como a nossa escola fica em uma avenida movimentada sempre oriento sobre a importância de atravessar na faixa, de prestar atenção aos carros, de ter atenção quando estão de bicicleta, entre outros" (P5).

Com o intuito de conhecer a prática dos professores, procuramos também identificar se em seus cotidianos os professores desenvolvem ações ou projetos que envolvem a educação para o trânsito ou sugestões para tal, apesar de não possuírem formação específica para isso. As professoras sinalizaram que:

[...] Não, creio que quanto mais próximo da realidade da criança o trabalho for realizado mais reflexões e ações práticas poderão ser desenvolvidas, tornando a criança como ser ativo no processo e não apenas um espectador. Busco tomar por base o contexto social em que a criança está inserida e suas vivências em relação ao trânsito (P1). 
[...] Não, sugiro atividades que trabalhem com a realidade, como as estatísticas de acidentes e mortes no trânsito, porque desde pequenos, os educandos devem aprender a analisar a realidade e o professor mediar essas situações é de fundamental importância para que eles entendam que a sociedade é feita de um grupo e não só por ele ou sua família (P2).

[...] Projetos não, apenas atividades bem pontuais na semana do trânsito (P3).

[...] não trabalho com ações ou projetos que envolvam a educação para o trânsito, pois para isso acredito ser necessária uma formação abrangente, além de ter em mãos materiais que possam me dar mais subsídios (P4).

Por sua vez, a professora P6 foi única em afirmar que "sim, em um dos projetos começamos a trabalhar o transitar no espaço escolar, desafios e possibilidades, com período de observações e condutas, desde a chegada até a saída, expandindo depois para o caminho até em casa e, por fim, no bairro de modo geral, foram várias as atividades vivenciadas no decorrer do semestre até uma culminância coletiva" (P6). Importante registrar que a professora faz parte da rede e que essa ação foi proveniente de sua participação como multiplicadora desse conhecimento adquirido em parceria com o Detran - PE no ano de 2010.

\section{Considerações finais}

Nossos resultados revelaram que a educação para o trânsito não vem sendo abordada como conteúdo curricular nos cursos de formação inicial de professores, nem como temática nas formações continuadas. Das seis professoras pesquisadas, apenas uma afirmou ter participado de um curso para multiplicadores. Elas sinalizaram, ainda, a influência que a educação para o trânsito exerce na redução e prevenção de acidentes, inclusive afirmando que é fator primordial a ser trabalhado desde a educação infantil.

Diante desses resultados, recomendamos a necessidade de se repensar as políticas de formação de professores e de educação básica voltadas para a educação para o trânsito, de forma que o conhecimento esteja integrado aos conteúdos das disciplinas e ao contexto de vida dos alunos, pois, se persistirmos com ações e campanhas pontuais, como àquelas vivenciadas durante a Semana Nacional do Trânsito, não conseguiremos promover uma tomada de consciência numa perspectiva transformadora e que atue em prol da humanização do humano (FREIRE, 2006).

Neste sentido, ressaltamos que, apesar de sinalizar a educação para o trânsito como tema transversal (PCN) a ser trabalhado nas escolas, as questões práticas precisam estar incluídas nos planejamentos e seguir objetivos específicos com um acompanhamento do aprendizado, inclusive com a participação dos pais e da comunidade na socialização das atividades, ampliando, assim, o envolvimento de todos acerca da temática.

Com o intuito de conhecer a prática das professoras, procuramos também identificar se ações ou projetos que envolvem a educação para o trânsito estavam presentes em sala de aula, porém cinco delas afirmaram que não. No entanto, mesmo negando a existência dessas práticas, sua pertinência também foi pontuada, traduzido nas suas falas através da importância de uma formação voltada para a cidadania. Mesmo sem formação específica, se revelaram preocupadas no seu cotidiano em orientá-los, utilizando-se de iniciativa e conhecimentos próprios.

Com isto, consideramos que a pesquisa apresentou resultados positivos, por contribuir tanto com a ampliação do conhecimento empírico, como uma releitura acerca dos aspectos legais. No entanto, recomendamos que os Projetos Pedagógicos dos Cursos - PPC de formação de professores possam contemplar a temática da educação para o trânsito, criando um leque de conhecimentos mais específicos para melhor trabalhar em sala de aula. 


\section{Referências}

BARDIN, L. Análise de conteúdo. Lisboa. Edições 70, 2002.

BRASIL. Departamento Nacional de Trânsito. Código de trânsito brasileiro. Disponível em: <http://www. denatran.gov.br/ctb.htm> Acesso em: 10 out. 2017.

BRASIL. Departamento Nacional de Trânsito. Resoluções do Contran. Disponível em: <http://www.denatran.gov.br/resolucoes.htm> Acesso em: 10 out. 2017.

BRASIL. Departamento Nacional de Trânsito. Diretrizes nacionais da educação para o trânsito na pré-escola. Disponível em: <http://www.denatran.gov.br/download/Portarias/2009/PORTARIA_DENATRAN_147_09_ANEXO_I_DIRETRIZES_PRE_ESCOLA.pdf> Acesso em: 10 out. 2017.

BRASIL. Departamento Nacional de Trânsito. Diretrizes nacionais da educação para o trânsito no ensino fundamental. Disponível em: <http://www.denatran.gov.br/download/Portarias/2009/PORTARIA_DENATRAN_147_09_ANEXO_II_DIRETRIZES_EF.pdf> Acesso em: 10 out. 2017.

BRASIL. Constituição da República Federativa do Brasil. Disponível em: <http://www.senado.gov.br/legislacao/const/con1988/CON1988_13.07.2010/CON1988.shtm> Acesso em: 10. Out. 2017.

BRASIL. Estatuto da criança e do adolescente. Disponível em: http://www.planalto.gov.br/ccivil_03/Leis/ L8069.htm Acesso em: 10 out. 2017.

BRASIL. Estatuto do idoso. Disponível em: <http://www.planalto.gov.br/ccivil_03/Leis/2003/L10.741. htm> Acesso em: 10 out. 2017.

BRASIL. Lei de diretrizes e bases da educação nacional. Disponível em: <http://www.planalto.gov.br/ccivil_03/Leis/L9394.htm> Acesso em: 10 out. 2017.

BRASIL. Secretaria de Educação Fundamental. Parâmetros curriculares nacionais. Brasília: MEC/SEF, 1997. CHAER, G; DINIZ, R. R. P; RIBEIRO, E. A. A técnica do questionário na pesquisa educacional. Evidência, Araxá, v. 7, n. 7, p. 251-266, 2011.

CZERWONKA, M. Indenizações por morte no trânsito aumentaram 27\% no primeiro semestre de 2017. Portal do Trânsito, 2017. Disponível em < http://portaldotransito.com.br/noticias/indenizacoes-por-morte-no-transito-aumentaram-27-no-primeiro-semestre-de-2017/> Acesso em: 03 out. 2017

FREIRE, Paulo. Educação como prática de liberdade. Rio de Janeiro: Paz e Terra, 2006.

GHIRALDELLI JR, Paulo. História da educação brasileira. 5. ed. São Paulo: Cortez, 2015.

GIL, Antônio Carlos. Métodos e técnicas de pesquisa social. 5. ed. São Paulo: Atlas, 1999.

MARTINS, João Pedro. A educação de trânsito: campanhas educativas nas escolas. Belo Horizonte: Autêntica, 2004.

MINAYO, M. C. de S. (Org.) Pesquisa Social: teoria, método e criatividade. Petrópolis: Vozes, 1994.

WERTHEIN, J. Jovens e o trânsito. Revista Linha Direta: Educação por Escrito. v. 10, n. 117, p. 8-9, dez. 2007.

Recebido em: 04.05.2019

Aprovado em: 08.05.2019

Para referenciar este texto:

SANTOS, Marcos Paulo Cavalcanti dos; SANTOS, Patrícia Irene dos. Educação para a humanização: por um trânsito mais consciente. Revista FAFIRE, Recife, v. 12, n. 1, p. 95-101, jan./jun. 2019. 